\title{
RIDDLE syndrome
}

INSERM

\section{Source}

INSERM. (1999). Orphanet: an online rare disease and orphan drug data base. RIDDLE syndrome. ORPHA:420741

A rare, genetic, primary immunodeficiency disorder characterized by increased radiosensitivity(R), mild immunodeficiency (ID), dysmorphic features (D), and learning difficulties (LE). 